\title{
A New Classification for Ad-Hoc Network
}

\author{
https://doi.org/10.3991/ijim.v14i14.14871 \\ Ahmed Refaat Ragab \\ October 6 University, Giza, Egypt \\ ahmed.refaat.csis@o6u.edu.eg
}

\begin{abstract}
This paper focuses on developing a new practical classification for ad-hoc networks, where all the past classifications revolve upon three main categories respectively, mobile ad- hoc network (MANET), Vehicle ad-hoc network (VANET) and Flying ad-hoc network (FANET). My new classification will illustrate Underwater vehicle ad-hoc network (UWVANET) as the fourth category in ad-hoc main classification, showing the powerful and the weakness of each category defined.
\end{abstract}

Keywords-Ad-hoc networks, MANET, VANET, FANET, UWVANET.

\section{Introduction}

The word ad-hoc is from Latin and means "for this (only)". The ad-hoc network is a subcategory of wireless network, but it is different with the purpose of infrastructure, as we can say that ad- hoc network is a network without an infrastructure as an access point, routers, etc. Ad hoc networks are widely used in both military and civilian applications, such as reconnaissance, attack role and rescue missions. In the purpose of communication, the ad-hoc networks communicate without establishing an intermediate nodes or cabling [1]. The main problems in ad hoc networks are routing and the characteristics of wireless communication, while in infrastructure's networks a node can communicate with all nodes in the same cell. In ad-hoc networks, the communication process depends upon selecting a specific routing algorithm, in other hand, the data transmission raises as a main problem, for its higher interferences and the possibility of asymmetric connections. Figure. 1 shows the main three categories, were ad-hoc network used to be classified by a lot of researchers as MANET, VANET and FANET, these categories based upon the main characteristic of the adhoc network, which is less infrastructure. This classification can be seen as it is dependable upon the usage of these networks, where the researchers neglect one of the most important uses of these networks, which is UWVANET. 


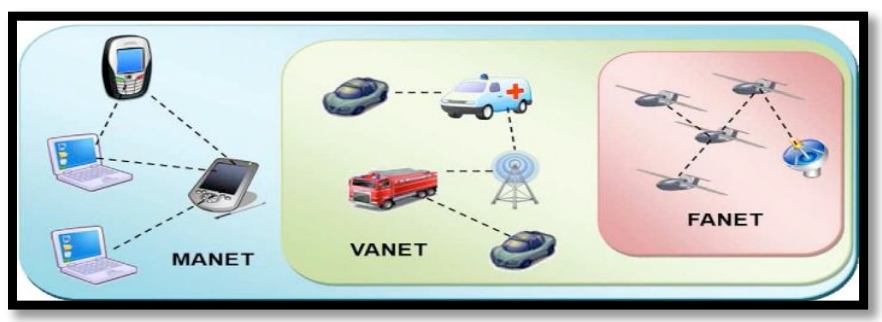

Fig. 1. The Old Classification of Ad-hoc network [5].

In this paper a new classification of ad-hoc network will be introduced, based on the functionality of the type of nodes being used. This paper is organized in seven sections as follows, Section 2 overview the ad-hoc networks, Section 3 studying Mobile ad-hoc network, Section 4 studying Vehicle ad-hoc network, Section 5 studying Flying ad-hoc network, Section 6 studying Underwater Vehicle ad-hoc network and finally section 7 concludes the paper.

\section{Overview Ad-Hoc Network}

The ad-hoc network can be thought as a set of separated wireless nodes, that communicate over a wireless communication medium, without the aid of any infrastructure as routers, access points, etc. These nodes must be characterized by a set of features, in order to overcome the limitation of the infrastructure absent, as routing protocol performance, processing capabilities and the transmission range [5].Although, the power of ad-hoc applications, but these types of networks are limited capabilities, due to the mobility, node density, topology changes, radio propagation, power consumption, network lifetime, computational power and localization [17].

Due to the variety and the widely usage of the ad-hoc network in many applications such as complex military system usage applied in resonance and attack roles, and civilian applications such as rescue missions and firefighting, the researchers built their classification for ad-hoc network, to be categories into three main categories respectively MANET, VANET and FANET, as shown in figure 1, while they didn't discuss in their classification beyond the ad-hoc nodes that operates underwater (UWVANET), despite of their powerful applications in military and civilian applications. The new classification for the ad-hoc network can be seen in figure 2, to be classified into four main categories respectively MANET, VANET, FANET and UWVANET. 


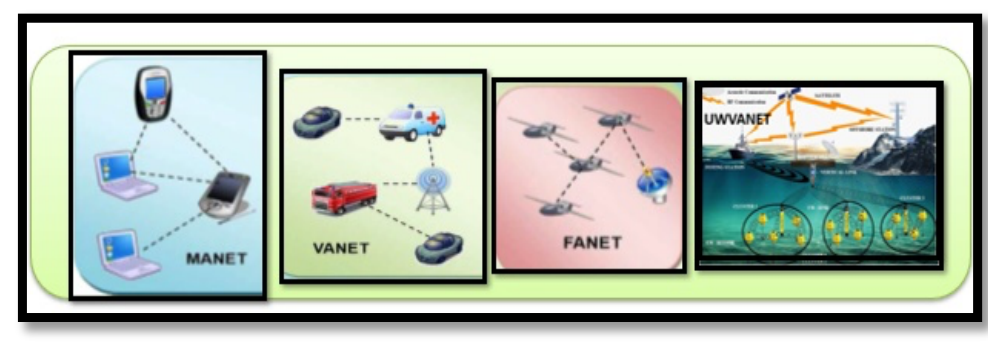

Fig. 2. New Classification of Ad-hoc network.

\section{Mobile Ad-Hoc Networks}

MANET is a set of mobile devices, that communicate through wireless medium, with the characterization of low power storage, less CPU processing and memory starvation. Routing, Mobility and the connectivity are created between the nodes, where it can be defined as peer level- multi hopping and this is the main point of view in Mobile Ad - hoc network.

Although, routing is created dynamically depending on the routing protocol used, to create a path from the source to the destination, this path may be shared by a lot of mobile nodes through the network to fulfill the network connectivity, during the this connectivity the wireless channel created is subjected with less bandwidth and it is affected by the path loss, noise and even interference. Convention, in distributed environment routing will not work because the topology can change rapidly. It was found that the routing algorithm which based on the shortest path is not applicable in the mobile ad-hoc networks, and to overcome this problem, a new routing algorithm are developed [18].

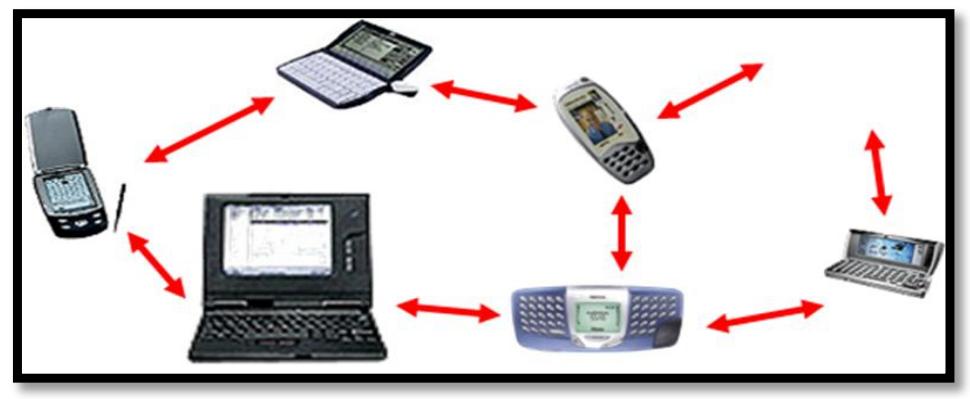

Fig. 3. Mobile Ad-hoc network.

Mobile ad-hoc network can be represented as an autonomous system because all hosts inside the network are connected by wireless connection and each host have the ability for movement in any direction (Mobility), also each node can be described as a router. Thus, MANET nodes operate as a router, and the entities inside the network 
topology dynamically changed, due to the variation in connectivity between the entities because any entity can depart any time and a new entity arrived [18].

\section{$4 \quad$ Vehicle Ad-Hoc Networks}

VANETs are a special case of mobile ad hoc networks (MANETs) [2]. In a VANET, the topology of the network can change more frequently as compared to MANET. VANETs are a special case of MANETs, VANET is represented in two structures, the first is the infrastructure of the roadside and the second, is the vehicle itself, as shown in fig.4. The usage of VANETs can be advertised in both military and civilian applications, ranging from search and rescue operations to road mapping and disaster monitoring [3]. VANETs can be represented as a mobile node working in a topology as a road, where the infrastructure of the roadside is fixed. This type of networking architecture is called Vehicle Ad-Hoc Networks (VANETs), which also have a unique challenge other than MANETs. The types of communication in VANETs play an important role in many researches, and it is classified into three major aspects, the first, is Vehicle-to-Vehicle, the second, is Vehicle-to-Infrastructure, and the third is the inter-roadside communication. And due to the high mobility of VANET networks, the network is changing rapidly, and the wireless link between each two nodes suffers from the rapid change in location, which is represented by the mobility, for this reason the links can be affected by disconnection [4].

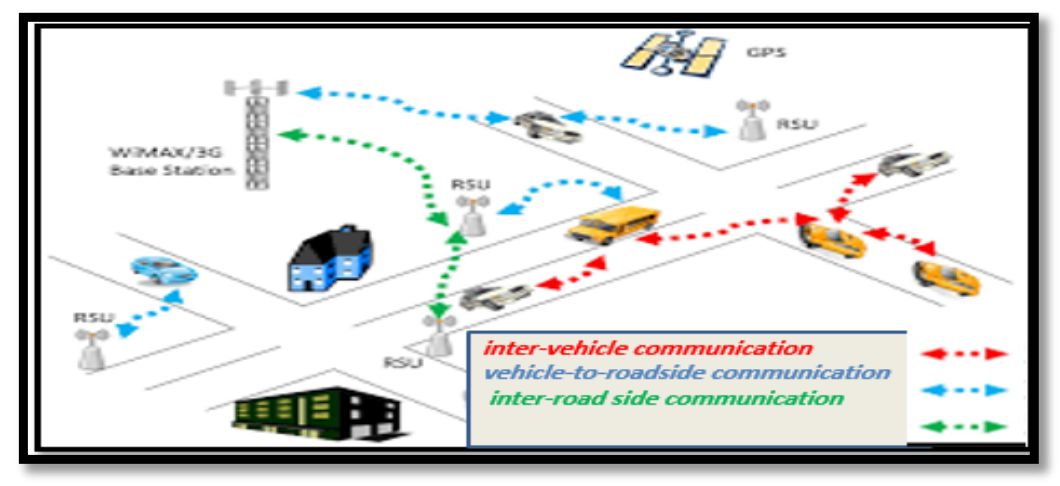

Fig. 4. Architecture of VANET [5].

From the above, it is noticed that VANET topology's, changes very frequently and the main of communication and all-time connectivity becomes an important limitation for the VANET based multi VANET task planning, also the distance between nodes is larger than in Manet, all these characteristics is due to the mobility of VANETs. Therefore, due to all these aspects, the rise of using a high gain antenna is required to obtain long range transmission, reduce hop count and enhance latency performance. The powerful of VANET make it capable of performing, real time operation, as a real 
video stream, where high data rate is required, this leads to high bandwidth requirements, when it is compared to MANET [7,8].

\section{$5 \quad$ Flying Ad-Hoc Networks}

FANETs are a special case of ad-hoc network and especially MANETs [5]. In a FANET, it is noticed the high mobility and the rapid topology change more than the other two types of ad-hoc network respectively, MANET and VANET. FANET is a combination of drones or we can say unmanned aerial vehicles, and it can be defined as a preprogramed autonomously plane's system that operates and works without the aid of a man on the board and the aid of infrastructure.

FANET, is a specialist network due to its powerful elasticity communication either through the satellite or the ground control station for establishing a link, channel or a connection-based communication, to be shared by all UAVs as shown in fig.5.

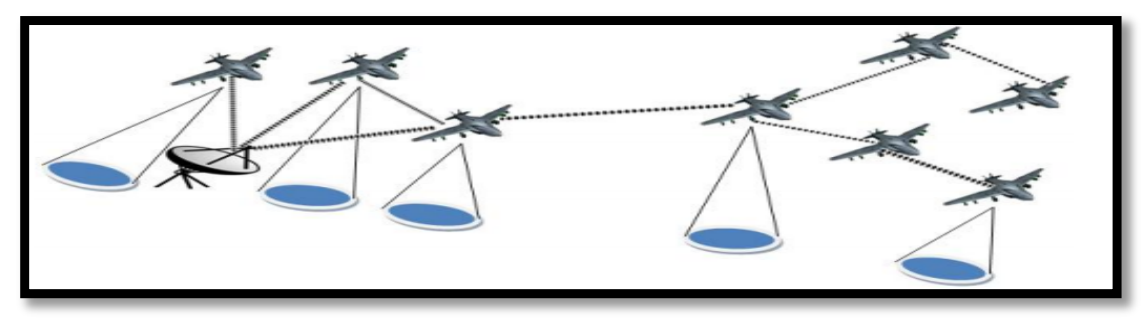

Fig. 5. UAVs Communication [19].

Effectively, FANET is the most powerful, efficient communication topology for the multi UAV systems, by the aid of its multi hop communication policy, FANET declare that all UAVs are well connected by each other or by the ground control station or even by the satellite system.

Thus, by studying the high mobility for the FANET systems with the rapid change in its architecture due to the nodes, frequent changes, the connectivity of the UAVs become an important issue because of the variable distance between the UAVs. The performance of the system must be equipped with the range achieved by the used antenna, so, as the long range of communication is required, this results in using a high gain antenna, the gain of the antenna results in reducing the hop count and reinforce latency execution. In missions, such as reconnaissance role the UAVs are supplied with highly sensitive cameras which required high video transmission in order to obtain real time action, also these systems required transmission of data in an accurate manner with high data rate. So, the system must obtain high bandwidth with high throughput more than any other ad-hoc networks. 


\section{Underwater Vehicle Ad-Hoc Network}

Underwater vehicle ad- hoc network is another important type of ad-hoc network, that may combine during its operation with wireless sensors in order to share and exchange information to enhance its functionality.

The importance of Underwater vehicle ad- hoc network had been viewed in the last several years, due to its rapid spread in many applications, especially military and civilian applications, as in oil-rig maintenance, Unmanned submarines, Unmanned Water Vehicle (UWV) and collection of data for water monitoring. The types of communication in UWVANETs play an important role, due to its widely used, and it is classified into four major aspects, the first, is Underwater vehicle-to-Underwater vehicle, the second, is Underwater vehicle-to-water surface, the third, is water surface-to-water surface, and finally the fourth, is water surface-to-Offshore station, as shown in fig.6.

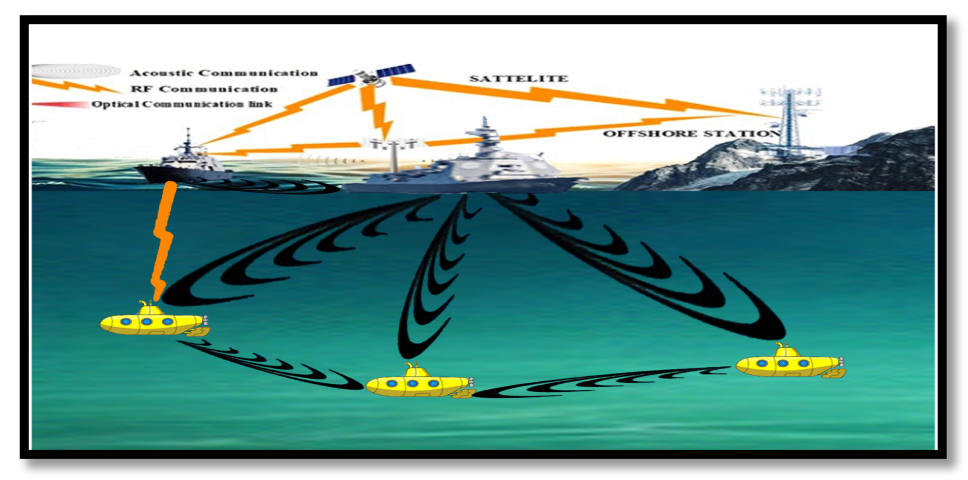

Fig. 6. UWVANETs Communication.

The main different between UWVANET and the other three types of ad-hoc network, is the communication methods used, where UWVANET can use the Acoustic communication, which can be defined as a method of communication depends upon Acoustic signals, which can be thought as dealing with the mechanics of waves in the fluids. Also, Underwater vehicle ad- hoc network, can use other types of communication technologies as radio frequency (RF) and Optical waves, table. 1 shows a comparison analysis, among Underwater vehicle ad- hoc network communication technologies, and it is clear that, when Acoustic communication is used, it gives high performance to the system in deep water, and this is cleared at the table.2. 
Table 1. Underwater vehicle ad- hoc network communication technologies [20].

\begin{tabular}{|l|l|c|c|c|c|c|l|}
\hline $\begin{array}{c}\text { Types of } \\
\text { Tech- } \\
\text { nology }\end{array}$ & Distance & $\begin{array}{l}\text { Propagation } \\
\text { Speed(m/s) }\end{array}$ & $\begin{array}{c}\text { Frequen- } \\
\text { cy }\end{array}$ & Bandwidth & Data rate & Attenuation & $\begin{array}{l}\text { Affecting factors } \\
\text { determine } \\
\text { channel quality }\end{array}$ \\
\hline RF & $\begin{array}{l}\text { Very short } \\
\text { distance } \\
\text { (Up to } 10 \\
\text { m) }\end{array}$ & $2.255 \times 10^{8}$ & $30-300 \mathrm{~Hz}$ & $\mathrm{MHz}$ & $\mathrm{Mbps}$ & $\begin{array}{l}\text { Frequency and } \\
\text { conductivity } \\
\text { dependent } \\
(3.5-5 \mathrm{~dB} / \mathrm{m})\end{array}$ & $\begin{array}{l}\text { Conductivity and } \\
\text { permittivity of } \\
\text { channel }\end{array}$ \\
\hline $\begin{array}{l}\text { Optical } \\
\text { waves }\end{array}$ & $\begin{array}{l}\text { Short } \\
\text { distances } \\
(\mathrm{Up} \text { to } \\
100 \mathrm{~m})\end{array}$ & $2.255 \times 10^{8}$ & $\begin{array}{c}10^{12}-10^{15} \\
\mathrm{~Hz}\end{array}$ & $\mathrm{MHz}$ & $\mathrm{Gbps}$ & $\begin{array}{l}0.39 \mathrm{~dB} / \mathrm{m} \\
(\text { Ocean }) \text { and } \\
11 \mathrm{~dB} / \mathrm{m} \\
(\text { Turbid water })\end{array}$ & $\begin{array}{l}\text { Absorption, scat- } \\
\text { tering, turbidity, } \\
\text { suspended and } \\
\text { organic matter of } \\
\text { channel link }\end{array}$ \\
\hline Acoustic & $\begin{array}{l}\text { Long } \\
\text { distance } \\
(\mathrm{Up} \text { to } 20 \\
\mathrm{km})\end{array}$ & 1500 & $10-1 \mathrm{kHz}$ & $\mathrm{Hz}$ & $\mathrm{kbps}$ & $\begin{array}{l}\text { Distance and } \\
\text { frequency } \\
\text { dependent } \\
(0.1-4 \mathrm{~dB} / \mathrm{m})\end{array}$ & $\begin{array}{l}\text { Absorption, scat- } \\
\text { tering, pressure, } \\
\text { temperature and } \\
\text { salinity of water } \\
\text { medium }\end{array}$ \\
\hline
\end{tabular}

Table 2. The possible Bandwidth for different Acoustic propagation distance [20].

\begin{tabular}{|l|c|c|c|}
\hline $\begin{array}{c}\text { Classified } \\
\text { Propagation } \\
\text { distance }\end{array}$ & $\begin{array}{c}\text { Possible range } \\
\text { (km) }\end{array}$ & $\begin{array}{c}\text { Maximum bandwidth } \\
\text { (Hz) }\end{array}$ & Possible data rate (kbps) \\
\hline Very Short & Less than 0.1 & More than 100 & 500 \\
\hline short & 0.1 to 1 & 20 to 50 & 30 \\
\hline Medium & 1 to 10 & Up to 10 & 10 \\
\hline Long & 10 to 100 & 2 to 5 & 5 \\
\hline Very long & more than 100 & Less than 1 & 600 \\
\hline
\end{tabular}

\section{Conclusion}

The important of ad- hoc network was cleared during the last several years, due to its impact usage in many fields, which lead me to sheds the light upon Underwater vehicle ad- hoc network, which is one of the most powerful type of this giant network (ad-hoc network).

This work can be thought as a kind of investigation upon ad-hoc network and its subcategories, it was found that the node mobility for underwater vehicle ad- hoc network is high depends upon many factors, such as the node speed, type of mission and the water environment, this lead the topology to change fast when it is compared to MANET or VANET.

It was found that the most important point of view, is choosing the best radio propagation technology to be used with Underwater vehicle ad-hoc network, and this is due to the environment that this network operates at, table. 3 collect the main issues of this investigation to be represented in the form of comparison between the four subcategories of ad-hoc network.

This work sheds the light upon an exist subcategory of ad-hoc network that was neglected during a lot of work and researches, which is Underwater vehicle ad- hoc network (UWVANET). 
Table 3. Comparison analysis for the four types of Ad-hoc Network.

\begin{tabular}{|c|c|c|c|c|}
\hline $\begin{array}{c}\text { Point of } \\
\text { comparison }\end{array}$ & MANET & VANET & FANET & UWVANET \\
\hline Node mobility & Low & High & Very high & High \\
\hline Mobility model & Random & Regular & $\begin{array}{l}\text { Regular for Predeter- } \\
\text { mined paths, But } \\
\text { special mobility models } \\
\text { for Autonomous multi- } \\
\text { UAV systems }\end{array}$ & $\begin{array}{l}\text { Regular for Predetermined } \\
\text { paths, But special mobility } \\
\text { models for Autonomous } \\
\text { multi-UWV systems }\end{array}$ \\
\hline Node density & Low & High & Very low & Very low \\
\hline $\begin{array}{l}\begin{array}{l}\text { Topology } \\
\text { change }\end{array} \\
\end{array}$ & Slow & Fast & Fast & Fast \\
\hline $\begin{array}{l}\text { Radio propaga- } \\
\text { tion model }\end{array}$ & $\begin{array}{l}\text { Close to } \\
\text { ground, LoS is } \\
\text { not available } \\
\text { For all cases }\end{array}$ & $\begin{array}{l}\text { Close to ground, LoS } \\
\text { is not available for } \\
\text { all cases }\end{array}$ & $\begin{array}{l}\text { High above the ground, } \\
\text { LoS is available for } \\
\text { most of the Cases. }\end{array}$ & $\begin{array}{l}\text { Depends upon a lot of } \\
\text { factors, such as the type of } \\
\text { technology used as shown } \\
\text { in table. } 1 \text {, and the propaga- } \\
\text { tion distance as shown in } \\
\text { table. } 2\end{array}$ \\
\hline \begin{tabular}{|l|} 
Power consump- \\
tion And net- \\
work lifetime
\end{tabular} & $\begin{array}{l}\text { Energy effi- } \\
\text { cient Protocols }\end{array}$ & Not needed & \begin{tabular}{|l|} 
Energy efficiency for \\
mini UAVs, But not \\
needed for small UAVs
\end{tabular} & $\begin{array}{l}\text { Energy efficiency for mini } \\
\text { UWVs, But not needed for } \\
\text { small UWVs }\end{array}$ \\
\hline $\begin{array}{l}\text { Computational } \\
\text { power }\end{array}$ & Limited & High & High & High \\
\hline Localization & GPS & GPS, AGPS, DGPS & $\begin{array}{l}\text { GPS, AGPS, DGPS, } \\
\text { IMU }\end{array}$ & GPS, AGPS, DGPS, IMU \\
\hline
\end{tabular}

\section{References}

[1] Martinus Dipobagio"An Overview on Ad Hoc Networks" IEEE Communications Magazine, 2002.

[2] kanta kumari, sunil maakar, basant sah," A Survey: Different Mobility Model for FANET", International Journal of Advanced Research in Computer Science and Software Engineering, Volume 5, Issue 6, June 2015.

[3] Dynamic Routing for Flying Ad Hoc Networks. Stefano Rosati, Member, IEEE, Karol Kru zelecki, Member, IEEE, Gr 'egoire Heitz, Dario Floreano, Senior Member, IEEE, and Bixio Rimoldi, Fellow, IEEE. https://doi.org/10.1109/tvt.2015.2414819

[4] Kanta Kumari, Basant Sah, Sunil Maakar"A Survey: Different Mobility Model for FANET"IJARCSSE, Volume 5, Issue 6, June 2015.

[5] Ahmed Refaat Sobhy, Mohamed M.Elfaham and Atalla Hashad" Fanet Cloud Computing" (IJCSIS),Vol. 14, No. 10, October 2016.

[6] Ahmed Refaat Sobhy, Abeer Twakol Khalil, Mohamed M.Elfaham and Atalla Hashad" UAV Cloud Operating System" MATEC Web of Conferences 188, 05011,ICEAF-V 2018. https://doi.org/10.1051/matecconf/201818805011

[7] Z. Han, A.L. Swindlehurst, K.J.R. Liu, Optimization of MANET connectivity via smart deployment/movement of unmanned air vehicle, IEEE Transactions on Vehicular Technology 58 (2009) 3533-3546. https://doi.org/10.1109/tvt.2009.2015953

[8] W. Wang, X. Guan, B. Wang, Y. Wang, A novel mobility model based on semi-random circular movement in mobile ad hoc networks, Information Science 180 (3) (2010) 399413. https://doi.org/10.1016/j.ins.2009.10.001 
[9] Ahmed Refaat Sobhy, Abeer Twakol Khalil, Mohamed M.Elfaham and Atalla Hashad" Cloud Robotics: A Survey " International Journal of Latest Research in Engineering and Technology, Volume 04 - Issue 05, May 2018, PP. 46-52.

[10] Dimitri Bertsekas, Robert Gallager "Data Networks," (2nd edition) Prentice Hall, 1992, ISBN 0-13-200916-1, Inc. Upper Saddle River, NJ, USA (C1992 .

[11] Md. Mamunur Rashid, Prithwiraj Datta" Performance Analysis of Vehicular Ad Hoc Network (VANET) Considering Different Scenarios of a City" International Journal of Computer Applications, Volume 162 - No 10, March 2017. https://doi.org/10.5120/ijca201791 $\underline{3329}$

[12] Wubben,Dirk; Rost,Peter; Bartelt,JensSteven; Lalam,Massinissa; Savin,Valentin; Gorgoglione, Matteo; Dekorsy, Armin; Fettweis, Gerhard" Benefits and Impact of Cloud Computing on 5G Signal Processing: Flexible centralization through cloud-RAN" Signal Processing Magazine, IEEE,2014,Volume ( 031 ),Issue: 006,page 35. https://doi.org/10.1109/ $\underline{\mathrm{msp}} .2014 .2334952$

[13] Maricela,Georgiana Avram" Advantages and challenges of adopting cloud computing from an enterprise perspective" The 7th International Conference Interdisciplinarity in Engineering (INTER-ENG 2013), Procedia Technology 12 ( 2014 ) 529 - 534. https://doi.org/10.10 16/j.protcy.2013.12.525

[14] Zain Tahir, Muhammad Aslam, Mishall Fatima" CLOUD COMPUTING INFLUENCE ON OPERATING SYSTEM" Sci.Int.(Lahore),27(1),225-230,2015.

[15] Jinzy Zhu" Cloud Computing Technologies and Applications" Handbook of Cloud Computing, Springer Science+Business Media, LLC 2010,pg 21-44.

[16] Subhrananda Goswami, Subhankar Joardar, Chandan Bikash Das" Reactive and Proactive Routing Protocols Performance MetricComparison in Mobile Ad Hoc Networks NS 2" International Journal of Advanced Research in Computer and Communication Engineering, Vol. 3, Issue 1, January 2014.

[17] İlker Bekmezci, Ozgur Koray Sahingoz, Şamil Temel"Flying Ad-Hoc Networks (FANETs): A survey"Ad Hoc Networks, Volume 11, Issue 3, May 2013, Pages 1254-1270. https://doi.org/10.1016/j.adhoc.2012.12.004

[18] Saleh Ali K.Al-Omari, Putra Sumari"an overview of mobile adhoc networks for the existing of protocols and applications"international journal on applications of graphs theory in wireless adhoc networks and sensor networks vol.2,No.1,March 2010. https://doi.org/10.51 21/igraphhoc.2010.2107

[19] Kanta Kumari, Basant Sah, Sunil Maakar"A Survey: Different Mobility Model for FANET"IJARCSSE, Volume 5, Issue 6, June 2015.

[20] Mohammad Furqan Ali, Dushantha Nalin K. Jayakodyy, Tharindu D. Ponnimbaduge Perera,Kathiravan Srinivasanz, Abhishek Sharmax and Ioannis Krikidis"Underwater Communications: Recent Advances"Conference: International Conference on Emerging Technologies of Information and Communications (ETIC), At JNEC, Bhutan,March 2019.

[21] Khaleel Ur Rahman Khan, Rafi U Zaman and A. Venugopal Reddy" An Analytical Framework for the Assessment of the Mobile IP overhead involved in the Integrated Internet-MANET" ,iJIM - Volume 4, Issue 1, January 2010. https://doi.org/10.3991/ijim.v4i1.1 $\underline{027}$

[22] Seibu Mary Jacob and Biju Issac " Mobile Technologies and its Impact - An Analysis in Higher Education Context", iJIM - Volume 2, Issue 1, January 2008.

[23] Saher Manaseer and Afnan Alawneh " Emergency Centers Set-up in the Existence of Ad Hoc

[24] Networks in Disaster Recovery Areas", iJES - Vol. 7, No. 1, 2019. 


\section{$9 \quad$ Author}

Ahmed Refaat Ragab is Doctor Engineer at the Faculty of Information Systems and computer Science, October 6 University.

He was graduated from Air Defense College, then got a diploma in computer engineering from the National telecommunication institute in Egypt with very good grades, and master degree in computer engineering from the college of engineering in the Arab Academy for Science and Technology and Maritime Transport, with excellent degree, and the thesis title was " Secure Routing In UAV".

Finally, he obtained the Degree of Doctor of Philosophy in Electrical Engineering, from the faculty of engineering, Benha University, with an excellent degree, and the thesis title was" UAV Cloud Computing System".

He works also as a lecturer for Communication Network, Electronics, Digital Image Processing and Distributed Systems at the faculty of information systems and computer science, October 6 University, also teaching Cisco courses as an instructor for cisco academy in October 6 university.

Article submitted 2020-04-15. Resubmitted 2020-05-06. Final acceptance 2020-05-07. Final version published as submitted by the authors. 